\title{
Fusión dental: reporte de un caso clínico
}

\author{
Carlos Colorado Vélez ${ }^{*}$ Esp.
}

${ }_{1}$ Facultad de Odontología, Universidad Cooperativa de Colombia, Medellín, Colombia

Recibido: 26 de agosto del 2014. Aprobado: 15 de octubre del 2014.

*Autor de correspondencia: Carlos Colorado. Facultad de Odontología, Universidad Cooperativa de Colombia, Medellín, Colombia. Carrera 42A n. ${ }^{\circ}$ 30-08.

Correo electrónico: endocolo@hotmail.com

Cómo citar este artículo: Colorado C. Fusión dental: reporte de un caso clínico. Rev Nac Odontol. 2014;10(19):101-6.

doi: http://dx.doi.org/10.16925/od.v10i19.850

Resumen. La fusión se define como la unión parcial o completa de dos o más dientes durante su desarrollo; puede ocurrir entre dos dientes normales o entre un diente normal y un supernumerario. Esta anomalía puede ser unilateral o bilateral y puede comprometer cualquier dentición, aunque los dientes deciduos son los perjudicados con mayor frecuencia. Además de afectar la apariencia del paciente, puede causar alteración del espacio en los arcos dentarios, caries y comprometer las estructuras periodontales. En este artículo, se presenta el caso de un joven de 13 años que acude a consulta por repetidos eventos inflamatorios a nivel de la encía vestibular del 22. Estos episodios tienen su causa en la fusión del 22 con un diente supernumerario. Tras la evaluación radiográfica y la planificación adecuada, el diente supernumerario fue extraído, y se eliminó así el surco palatino que se formaba por la fusión de ambos dientes, causa principal de la lesión perioendodóntica que presentaba el paciente.

Palabras clave: fusión dental, dentición permanente, supernumerario.

\section{Dental Fusion: Report on a Clinical Case}

Abstract. Fusion is defined as the partial or complete union of two or more teeth during their development; it can occur between normal teeth or between a normal tooth and a supernumerary tooth. This anomaly can be unilateral or bilateral and can affect any teeth, although deciduous teeth are more frequently damaged. It can also affect the patient's appearance, cause changes in the dental arch space, lead to cavities and affect periodontal structures. This article presents the case of 13-year-old who came in for consultations due to repeated inflammatory events at the level of gum 22. These episodes stem from the fusion of tooth 22 with a supernumerary. After radiographic evaluation and adequate planning, the supernumerary tooth was extracted, and the palatal groove formed by the fusion of both teeth was eliminated, which had been the main cause of the patient's periodontal-endodontic lesion.

Keywords: dental fusion, permanent teeth, supernumerary.

\section{Fusão dental: reporte de um caso clínico}

Resumo. A fusão define-se como a união parcial ou completa de dois ou mais dentes durante seu desenvolvimento; pode ocorrer entre dois dentes normais ou entre um dente normal e um supranumerário. Esta anomalia pode ser unilateral ou bilateral e pode comprometer qualquer dentição, ainda que os dentes decíduos são os prejudicados com maior frequência. Além de afetar a aparência do paciente, pode causar alteração do espaço nos arcos dentários, cárie e comprometer as estruturas periodontais. Neste artigo, apresenta-se o caso de um jovem de 13 anos que vai a consulta por repetidos eventos inflamatórios na região gengival vestibular do 22. Estes episódios são causados pela fusão do 22 com um dente supranumerário. Depois da avaliação radiográfica e o planejamento adequado, o dente supranumerário foi extraído, e eliminou-se assim o sulco palatino que se formava pela fusão de ambos dentes, causa principal da lesão perioendodôntica que apresentava o paciente.

Palavras-chave: fusão dental, dentição permanente, supranumerário. 


\section{Introducción}

La fusión dental consiste en la unión de dos gérmenes dentarios en desarrollo, que da lugar a un diente que suele tener un tamaño mayor a lo normal. La unión de los dos gérmenes dentarios puede suceder en cualquiera de los estadios de desarrollo del germen dental a partir de la lámina dentaria (brote, casquete o campana), o en los más avanzados procesos de diferenciación [1].

Cuanto más precoz sea la unión, más completa será la fusión resultante. La unión puede obedecer a factores hereditarios, pero en ocasiones la causa puede ser la existencia de factores traumáticos con presión de un germen sobre otro, que fuerza el contacto entre ambos y da lugar a la posterior unión. La fusión dentaria es mucho más frecuente en dientes temporales que en permanentes; la incidencia oscila entre 0,5 y $1 \%$ para los dientes temporales y un $0,1 \%$ en los permanentes. Los más afectados son siempre los dientes anteriores [2].

Asimismo, las fusiones pueden ser bilaterales o afectar a un diente aisladamente. La unión se produce generalmente por la dentina, y puede afectar la totalidad del diente (fusión total) o limitarse a la corona o la raíz (fusión parcial). Cuanto más temprana en el desarrollo embriológico sea la unión, más completa será la fusión; y cuanto más tardía, mayor será el tamaño del diente resultante, y más evidentes los signos de estar dos dientes unidos [3].

$\mathrm{El}$ aspecto morfológico de las fusiones y de la geminación es idéntico. La diferencia estriba en que en la fusión hay una reducción del número de dientes. Por eso, siempre debemos contar este número para ver si se corresponde con el de la fórmula dentaria normal. Si faltan dientes y hay alguno más grande o con signos de duplicidad, muy probablemente será una fusión. En ocasiones, la fusión se da entre un diente normal y un supernumerario, casos en los que es difícil establecer si es o no fusión, pues no habrá reducción de la fórmula dentaria [4]. Con frecuencia, la fusión se acompaña de surcos y fisuras adicionales muy profundos, que con facilidad son asiento de lesiones periodontales y endodónticas [1-4].

El propósito de este artículo es reportar la experiencia lograda y el protocolo aplicado en el diagnóstico y tratamiento de un caso de fusión dental.

\section{Caso clínico}

Paciente de 13 años de edad, de género masculino, quien consulta al endodoncista por presentar salida de tracto sinuoso en encía vestibular de 22 . El paciente se observa en buenas condiciones de salud general; en la anamnesis complementaria, no se hallaron desórdenes sistémicos o anomalías en su historia personal ni familiar. Al examen clínico se observa alteración en la fórmula dental, y se detecta fusión dental de 22 con diente supernumerario y salida de tracto sinuoso en encía adherida a nivel de 22 fusionado con diente supernumerario (figuras 1 y 2 ).

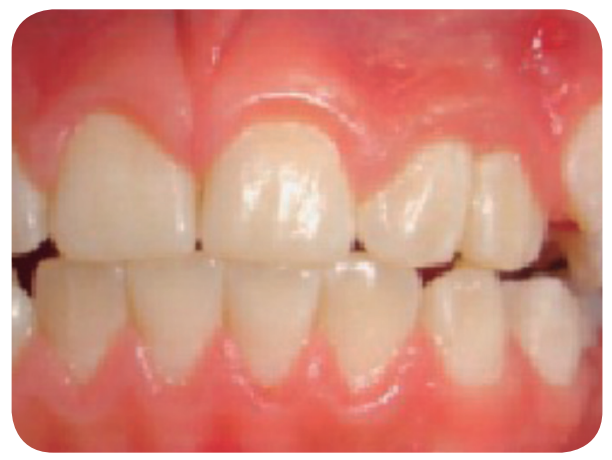

Figura 1. Paciente de trece años, masculino, con fusión de dos incisivos (lateral y supernumerario)

Fuente: caso clínico

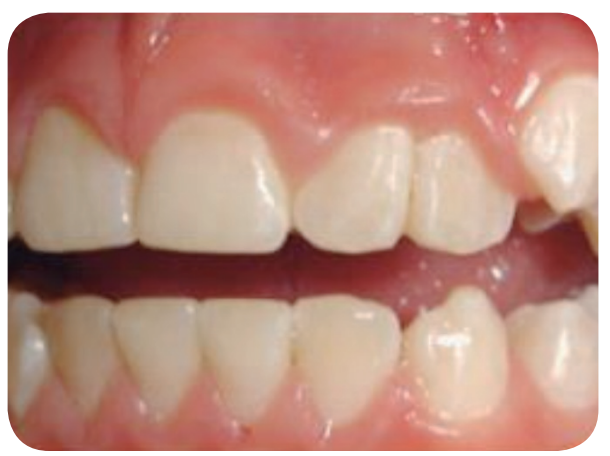

Figura 2. Observe la salida del tracto sinuoso y la falta de espacio para el canino

Fuente: caso clínico

Los dos dientes se encontraban fusionados totalmente en las coronas; no se observó presencia de caries, pero sí gran retención de placa bacteriana. En palatino 
se detectó bolsa periodontal profunda originada por el surco palatino que se formaba por la fusión de ambos dientes, que además era la causa del defecto periodontal y de la lesión apical que presentaba el paciente.

Ninguno de los dientes respondió a las pruebas de sensibilidad (vitalómetro, Endo-Ice). El análisis radiográfico revela la presencia de dos dientes fusionados con raíces y conductos radiculares independientes, y una imagen radiolúcida apical lateral al diente supernumerario de gran tamaño compatible con lesión apical (figuras 3 y 4 ).

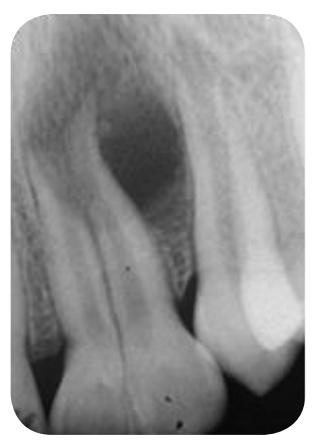

Figura 3. Aspecto radiográfico: fusión de las coronas y lesión apical

Fuente: caso clínico

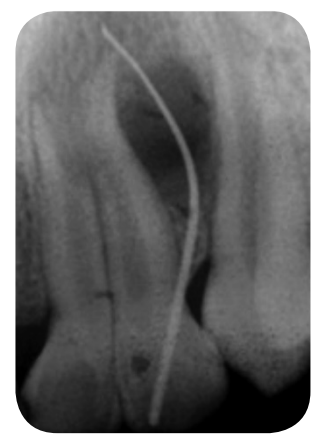

Figura 4. Fistulografía a través del tracto sinuoso Fuente: caso clínico

El paciente fue sometido a un procedimiento quirúrgico para separar los dientes fusionados y extraer el diente supernumerario, a fin de eliminar el surco palatino que se formaba por la fusión de ambos y que era el origen de la lesión periapical que presentaba el paciente; además, se crea espacio para la posición correcta del canino (figuras 5-15).

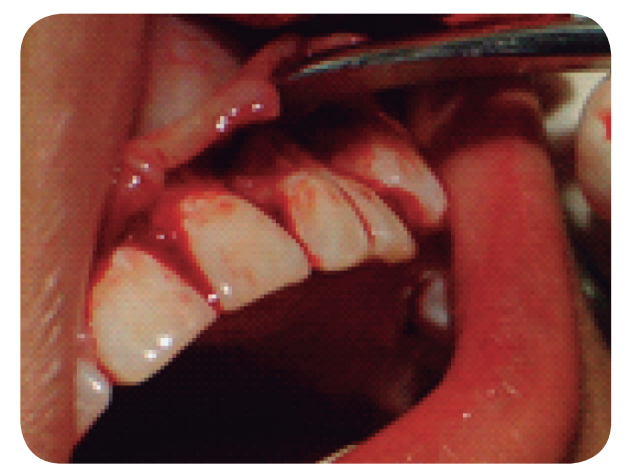

Figura 5. Procedimiento quirúrgico para la separación de los dientes fusionados

Fuente: caso clínico

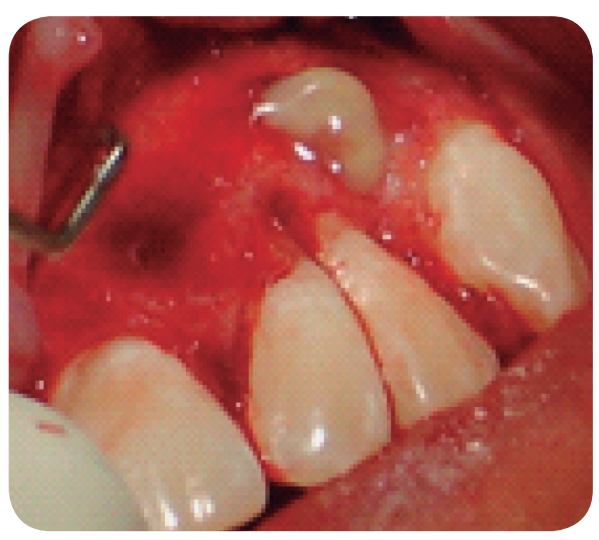

Figura 6. Salida abundante de material purulento de la lesión apical generada

Fuente: caso clínico

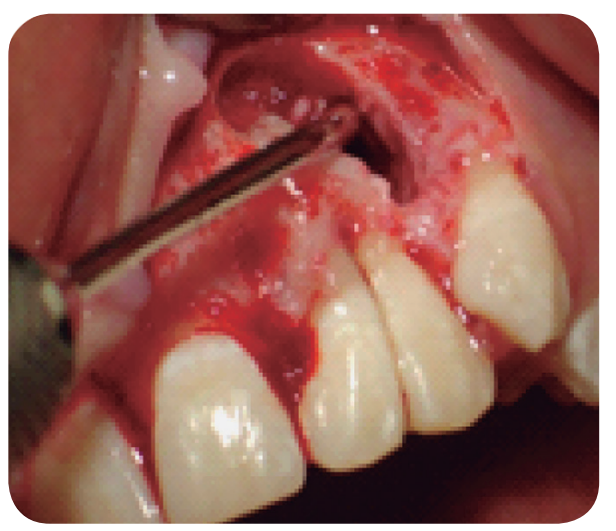

Figura 7. Aspecto de la reabsorción ósea generada por la lesión apical

Fuente: caso clínico 
No se hizo endodoncia en el diente remanente debido a que la cámara pulpar y el conducto radicular quedaron expuestos al periodonto; solo fueron conformados con ultrasonido para eliminar el tejido pulpar remanente. Luego, se hizo selle cameral con MTA y restauración del diente con resina, con lo que se consiguió mejorar el aspecto estético del paciente.

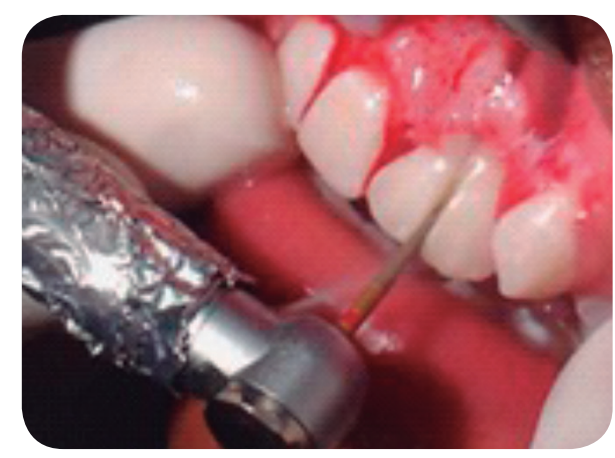

Figura 8. Separación de las coronas fusionadas con fresa de diamante $n .^{\circ} 700$

Fuente: caso clínico
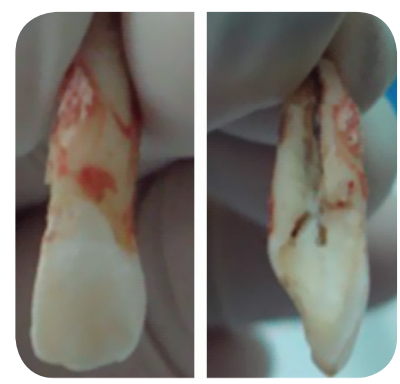

Figura 9. Aspecto bucal e interproximal del diente supernumerario extraído

Fuente: caso clínico

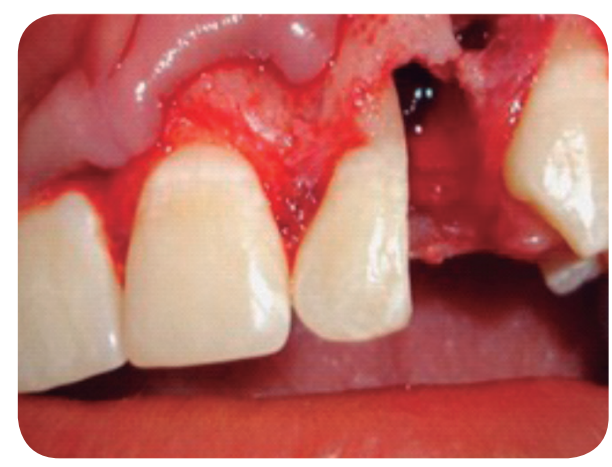

Figura 10. Aspecto clínico después de la extracción del supernumerario fusionado

Fuente: caso clínico

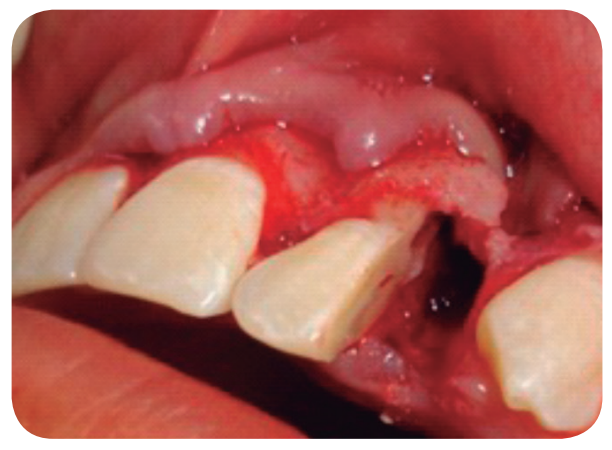

Figura 11. Aspecto clínico después de la extracción del supernumerario fusionado, vista lateral

Fuente: caso clínico

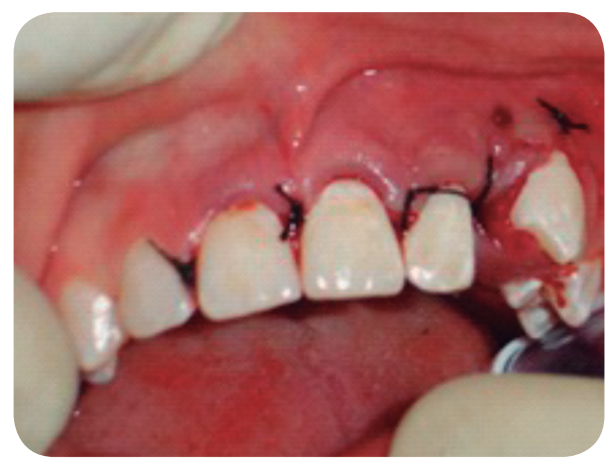

Figura 12. Reposición del colgajo

Fuente: caso clínico

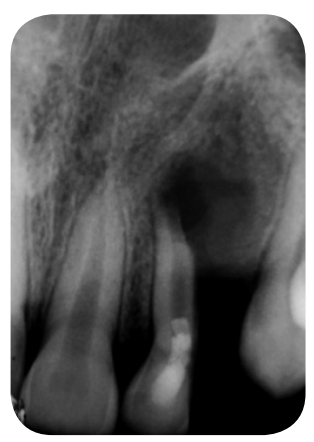

Figura 13. Aspecto radiográfico después de la extracción del supernumerario fusionado

Fuente: caso clínico 


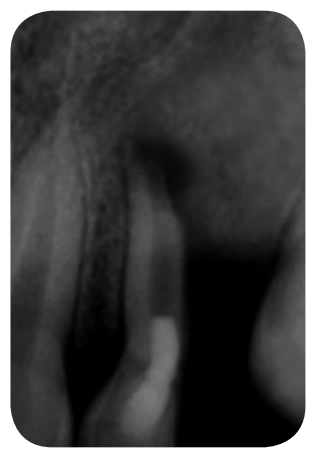

Figura 14. Aspecto radiográfico tres meses después Fuente: caso clínico

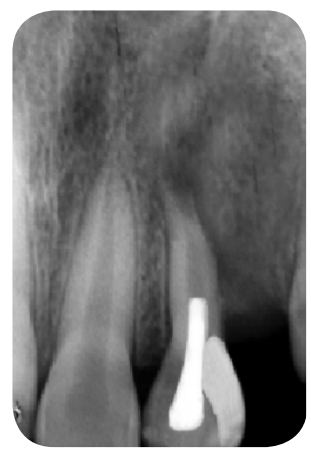

Figura 15. Aspecto radiográfico nueve meses después Fuente: caso clínico

\section{Discusión}

La fusión dental es una anomalía asintomática, que puede causar problemas clínicos como alteraciones estéticas, apiñamiento, retención de placa dental, caries dental, y si el surco prominente que los divide en la superficie labial y palatina se continúa hasta la superficie radicular, posiblemente producirá patología periodontal [2-5].

De allí que el manejo clínico sea interdisciplinario y que el procedimiento quirúrgico sea utilizado para separar los dos dientes constituye una buena alternativa de solución conservadora, dada la presencia de cámaras pulpares y de conductos radiculares independientes [6].

Aunque su etiología no ha sido aclarada, algunos investigadores la atribuyen a la participación de alguna fuerza o evento que causa la aproximación física durante el desarrollo de los gérmenes de los dientes comprometidos. También, se ha reportado la tendencia hereditaria como factor importante en la ocurrencia de la fusión $[7,8]$.
Se han utilizado diferentes procedimientos para el tratamiento de estos dientes, muchos de ellos interdisciplinariamente. Kayalibay et al. [9] reportaron un caso de fusión de incisivo central superior izquierdo a un diente supernumerario en su cara vestibular, que se intervino con extracción quirúrgica, hemisección y luego reimplantación y ortodoncia. Como secuela, se presentó reabsorción radicular.

Maréchaux [10] también describió una fusión entre un incisivo central superior derecho con un diente supernumerario en un niño de nueve años de edad, y se procedió a separarlo mediante un abordaje quirúrgico. Hülsmann y Grohmann [11] reportaron un caso de fusión de incisivo central permanente con supernumerario, que igualmente trataron con cirugía de hemisección, restauración con resina híbrida y, tres meses más tarde, tratamiento ortodóncico.

\section{Conclusión}

El tratamiento de este tipo de anomalías debe enfocarse desde un punto de vista integral, de acuerdo con los resultados del diagnóstico clínico y radiográfico, basado en el compromiso de la unión histológica de los dientes.

Según el caso clínico reportado, el hecho de que no se compartiera la cámara y los conductos pulpares permitió guiar el tratamiento hacia la separación quirúrgica de los dientes fusionados y hacia la extracción del diente supernumerario, con lo que se eliminó el surco palatino creado por la fusión de ambos, causa principal de la lesión apical. No hubo necesidad de hacer tratamiento endodóntico, puesto que la cámara pulpar y el conducto radicular quedaron expuestos a los tejidos periodontales. El procedimiento permitió corregir el compromiso estético del paciente y eliminar la etiología de la lesión apical. Además, se creó el espacio suficiente para la erupción y acomodación adecuada del canino en el arco dental.

\section{Referencias}

[1] Duncan WK, Helpin ML. Bilateral Fusion and Gemination: A Literature Analysis and Case Report. Oral Surg Oral Med Oral Pathol. 1987;64(1):82-7.

[2] Haskell TD, Krakowiak PA, Pirani AB. Non-Endodontic Coronal Resection of Fused and Geminated Vital Teeth. A New Technique. Oral Surg Oral Med Oral Pathol Oral Radiol Endod. 1997;83(4):501-5. 
[3] Prabhakar AR, Marwah N, Raju OS. Triple Teeth: Case Report of an Unusual Fusion Three Teeth. J Dent Child. 2004;71(3):206-8.

[4] Cubukcu CE, Sonmez A, Gultekin V. Labial and Palatal Talos Cusps on Geminated Tooth Associated with Dental Root Shape Abnormality: A Case Report. J Pediatr Dent. 2006;31(1):21-4.

[5] Brook AH, Winter GB. Double Teeth: a Retrospective Study of "Geminated" and Fused Teeth in Children. Br Dent J. 1970;129(3):123-30.

[6] Croll TP, Rains NJ, Chen E. Fusion and Gemination in One Dental Arch: Report of a Case. J Dent Child. 1981;48:297-9.

[7] Nunes E, Gomes de Moraes I, De Oliveira Moraes PM, Galvão de Sousa SM. Bilateral Fusion of Mandibular Se- cond Molars with Supernumerary Teeth: Case Report. Braz Dent J. 2002;13(2):137-41.

[8] Kohavi D, Shapira J. Tissue Regeneration Principles Applied to Separation of Fused Teeth. J Clin Periodontol. 1990;17(9):623-9.

[9] Kayalibay H, Uzamis M, Akalin A. The Treatment of a Fusion between the Maxillary Central Incisor and Supernumerary Tooth: Report of a Case. J Clin Pediatr Dent. 1996;20(3):237-40.

[10] Maréchaux SC. The Treatment of Fusion of a Maxillary Central Incisor and a Supernumerary: Report of a Case. J Dent Child. 1984;51(3):196-9.

[11] Hülsmann M, Bahr R, Grohmann U. Hemisection and Vital Treatment of a Fused Tooth-Literature Review and Case Report. Endod Dent Traumatol. 1997;13(6):253-8. 